\title{
O espelho imperfeito: a poesia de Hilda Hilst e sua versão para o inglês
}

\author{
Frederico Spada Silva ${ }^{1}$
}

\begin{abstract}
Resumo: O presente artigo propõe a análise de uma versão para o inglês, realizada por Lavinia Saad em seu blog "Brazilian Poetry in Translation: Translations and Transfigurations", do primeiro poema da seção "Dez chamamentos ao amigo", que é parte do livro Júbilo, memória, noviciado da paixão (1974), da poetisa paulista Hilda Hilst (1930-2004), a partir da comparação entre os textos fonte e alvo e de teorias e procedimentos tradutórios que reforçam o caráter literal, mas não de equivalência, da versão em questão. Para tanto, começamos discutindo algumas questões relativas ao texto literário, em especial a poesia, e ao papel do tradutor em sua relação com a tradução/versão literária; em seguida, apresentamos a vida e a obra de Hilda Hilst, comentando o livro que faz parte de nosso corpus, para, por fim, apresentamos nossa análise da versão de Saad para o referido poema, abordando seu trabalho tanto do ponto de vista formal quanto estrutural.
\end{abstract}

Palavras-chave: Versão. Poesia. Hilda Hilst.

The imperfect mirror: Hilda Hilst's poertry and its enflish version

\begin{abstract}
This article aims at analyzing an English version of the opening poem of the section entitled "Dez chamamentos ao amigo" (Ten appeals to a friend), from Hilda Hilst's book called Joy, Memory, Novitiate of Passion (1974), translated by Lavínia Saad in her blog "Brazilian Poetry in Translation: Translations and Transfigurations". This analysis is done by comparing the source and the target texts and using translational procedures and theories that confirm the literal, but non-equivalent, aspect of the discussed version. To do so, we first begin by discussing some questions concerning the literary text, with a special focus on poetry, and the translator's role and his relation with the literary translation/version; then, we present Hilst's life and work and comment the book which is part of our corpus, in order to finally present an analysis of Saad's version for that poem, considering her work by a point of view both structural and formal.
\end{abstract}

Keywords: Version. Poetry. Hilda Hilst.

\section{Introdução}

\footnotetext{
${ }^{1}$ Doutorando em Literatura, cultura e contemporaneidade (PUC-Rio), mestre em Estudos literários (UFJF). E-mail para contato: fredspada@gmail.com.
} 
O presente artigo propõe a análise de uma versão ${ }^{2}$ para o inglês, feita por Lavínia Saad em seu blog "Brazilian Poetry in Translation: Translations and Transfigurations", do primeiro poema da seção "Dez chamamentos ao amigo", que compõe o livro Júbilo, memória, noviciado da paixão (1974), da poetisa paulista Hilda Hilst (1930-2004).

O trabalho consiste na leitura comparativa dos textos fonte e alvo tanto à luz de teóricos da tradução que se dedicam ao estudo das traduções literárias, como De Causatis e Furlan, como a partir dos procedimentos tradutórios estudados por Barbosa, o que nos permite perceber o caráter literal da versão em questão, isto é, a conservação, no textoalvo, de uma fidelidade semântica entre as línguas de origem e de destino, sem que isso signifique uma equivalência absoluta para com o texto original (no sentido de uma correspondência sintagmática exata e direta entre as línguas), mas, sim, um processo de reescritura, por parte da tradutora, para que o texto-alvo se aproxime do texto-fonte, como comenta Furlan (1998, p. 101) a respeito da teoria da tradução de Meschonnic.

Para tanto, começamos propondo a discussão de questões relativas à tradução/versão de obras literárias, especialmente sob a ótica de algumas peculiaridades do texto poético e do papel do tradutor (seção 2); em seguida, apresentamos a vida e a obra de Hilda Hilst, com destaque para o livro que faz parte de nosso corpus, de modo a explicitar o contexto histórico e temático de sua escrita (seção 3). Posteriormente, apresentamos nossa análise da versão de Saad a partir de sua comparação com o texto original (seção 4) e, por fim, uma conclusão a seu respeito.

\section{O texto poético e os desafios de sua tradução/versão}

Em $O$ arco e a lira (1982), Paz delineia os limites do poema a partir de três elementos: ritmo, imagem e sentido. O ritmo, o mais antigo e permanente elemento da linguagem, é essencial ao poema, uma vez que neste o ritmo se manifesta por completo, enquanto que, na prosa, ele deixa de ser essencial, porque dele se desprendem as palavras, que estão sustentadas pela razão. O ritmo vai além das palavras soltas, da quantidade de

\footnotetext{
${ }^{2}$ Optamos pelo termo versão, em vez de tradução, para nos referirmos ao trabalho da tradutora, por se tratar de uma passagem de um texto em L1 (português) para L2 (inglês).
} 
sílabas na frase, da prosódia: é também imagem e sentido, e com eles forma o verso, a frase poética - e o verso livre, cuja unidade é dada pela imagem, e não pela medida externa (métrica), é também uma unidade rítmica, dotada de musicalidade.

Fugindo das acepções corriqueiras do que seja a imagem, Paz liga intimamente seu entendimento à poesia: "designamos com a palavra imagem toda forma verbal, frase ou conjunto de frases, que o poeta diz e que unidas compõem um poema" (ibidem, p. 119). Comum a qualquer imagem é a sua característica de preservar os muitos significados de uma palavra (sua plurissignificação), mesmo que contrários ou díspares, sem que, com isso, a frase de que participa se torne incompreensível. Como o autor mexicano argumenta, a poesia, dessa forma, ao explicitar os contrários, foge do pensar lógico - e é por isso que não pode aspirar à verdade, pois há uma realidade própria à poesia, não a do que é, mas a do que poderia ser. Isso porque a operação unificadora da imagem se afasta daquelas que trabalham outras formas de expressão da realidade: enquanto nossas versões do real apenas representam ou descrevem o que pretendem exprimir, o verso evoca, desperta nossa experiência do real, apresentando-a a nós. O sentido da poesia, conclui Paz, são as imagens do poema, isto é, sentido e imagem são a mesma coisa, porque a imagem poética explicase a si mesma, coloca-nos diante de uma realidade concreta - diferentemente da prosa, cujo sentido está sempre a nos levar a outra coisa.

A presença destes conceitos acerca do texto poético tem, em nosso trabalho, duas razões: não apenas porque se trata de um artigo dedicado à análise da versão de um poema para o inglês, na qual aspectos como ritmo, imagem e sentido serão discutidos, mas também porque precisamos nos atentar para as diferenças essenciais que separam o texto literário, em especial a poesia, do texto não literário, uma vez que tradução de ambos exige do tradutor esforços distintos. Ao tentarmos estabelecer os limites que os separam, percebemos que é na linguagem que residem: enquanto a linguagem não literária se mostra objetiva, prosaica, fechada em um conjunto delimitado de significações (o que é condição sine qua non para sua objetividade), a linguagem literária, poética principalmente, explode em possibilidades de leitura, porque tem por base uma escrita subjetiva que explora a plurissignificação, tornando o texto aberto a variadas interpretações. 
Desse modo, como aponta De Causatis (2008, p. 13 e ss.), um primeiro desafio criado pela tradução é o de se assumir uma missão ética que permita haver um trabalho o mais transparente possível de mediação entre duas culturas, a da obra em questão e a de seu novo público leitor, ainda que erigido de uma leitura sempre parcial e subjetiva do tradutor, o qual detém um duplo papel diante do texto, o de leitor crítico do original, interpretando-o, e, a partir desta leitura, o de autor de seu correspondente na língua de destino. Para tanto, é fundamental que o tradutor conheça bem as línguas e os sistemas literários e culturais envolvidos, tanto no que se refere ao texto de partida quanto ao texto de chegada, para que seu trabalho não desqualifique o original, permitindo aos novos leitores a compreensão daquilo que a obra original tem a oferecer. Além disso, o tradutor deve ter em mente que o texto de chegada não é a imagem especular, simétrica do de partida, mas um novo texto em conformidade, em fidelidade com o que lhe origina.

Assim, como afirma Furlan a respeito da teoria da tradução de Meschonnic, "a tradução é possível, e o é porque é escritura, re-escritura, re-textualização, traduçãotexto" (FURLAN, 1998, p. 101), o que não apenas realça o caráter autoral da tarefa do tradutor, como também destaca que ao tradutor cabe escolher, entre as leituras possíveis que pode fazer do texto original, aquela que melhor se adéqua à língua de chegada, conservando, como já dito, a identidade e o conteúdo do texto-fonte - ou, nas palavras de Paz:
a atividade do tradutor é parecida com a do leitor e a do crítico: cada leitura é uma tradução, e cada crítica é, ou começa a ser, uma interpretação (...) [;] em um segundo momento, a atividade do tradutor é paralela à do poeta, com esta diferença marcante: ao escrever, o poeta não sabe somo será seu poema; ao traduzir, o tradutor sabe que seu poema deverá reproduzir o poema que tem diante dos olhos. (...) $\mathrm{O}$ poema traduzido deverá reproduzir o poema original, que, como já foi dito, não é sua cópia e sim sua transmutação. (PAZ, 2006, p. 13)

Percebemos, portanto, a partir deste percurso teórico que vimos seguindo, que tanto o tradutor quanto a tarefa da tradução carregam consigo um duplo viés: enquanto o primeiro deve ser ao mesmo tempo um leitor-crítico e um escritor, consciente de suas escolhas em cada um de seus atos, esta última consiste em uma atividade de produção, e não de cópia, cujo produto final ao mesmo tempo guarda conformidade para com seu modelo e adquire autonomia enquanto texto em sua língua de chegada. 


\section{Hilda Hilst: vida e obra}

Tendo em mente as peculiaridades do tex to literário discutidas acima, bem como as de seu trabalho de tradução/versão, passemos agora a uma contextualização da obra de Hilda Hilst, de modo a preparar-nos para o poema que será alvo de nossa posterior análise.

Hilst nasce em 1930, em Jaú, interior de São Paulo. Começa a cursar Direito em 1948, na Faculdade de Direito do Largo de São Francisco, e, em 1950, vem a público seu primeiro livro, Presságio, volume de poemas. Desde o começo de sua formação acadêmica conhece uma vida boêmia que perdura até 1963, ano em que se muda para os arredores de Campinas e passa a se dedicar integralmente à literatura, mostrando-se uma autora multifacetada, com incursões bem sucedidas na dramaturgia, na prosa de ficção e na crônica. Morre em 2004.

Primeiramente publicada por pequenas editoras, a reunião de sua obra por uma grande editora ${ }^{3}$ atendeu a um desejo da escritora em ampliar seu público leitor, desejo esse manifestado em entrevistas concedidas a jornais e revistas, especialmente a partir dos anos 1980. Lida quase exclusivamente pela academia, que bem a acolhia criticamente, ainda que acusasse certo hermetismo em sua escrita, e refém das pequenas tiragens em editoras de pouca ou nenhuma distribuição, Hilda Hilst queria ser lida por um público diverso e numeroso, como ela mesma dissera em entrevista concedida ao jornal $O$ Globo de 11 de novembro de 1990: "Antes de morrer eu queria ser consumida, queria ver as pessoas lerem, porque não tem cabimento escrever a vida inteira para ninguém ler" (apud SOUZA, 2008, p. 12).

Tanto seu desejo de ampliar o público leitor, como visto acima, quanto sua relação com o mercado editorial revelam uma escritora consciente e crítica dos jogos de interesse que dominam esse nicho da indústria cultural na sociedade de consumo capitalista. A autora paulista soube trazer para sua obra um embate fundamental em

\footnotetext{
${ }^{2}$ A editora Globo iniciou, em 2001, a publicação de toda a obra de Hilst: poesia, prosa de ficção, crônica e teatro. Em 2013, o selo Biblioteca Azul, da própria Globo, publicou Fico besta quando me entendem, uma reunião organizada por Cristiano Diniz de vinte entrevistas concedidas pela autora.
} 
tempos dominados pela cultura de massa: aquele entre a alta cultura, presente em sua obra poética e prosaica iniciais, e a baixa cultura, caminho de cujo viés temático se aproxima com a publicação de sua trilogia obscena, composta pelos volumes em prosa

O caderno rosa de Lori Lamby (1990), Contos d'escárnio/Textos grotescos (1990) e Cartas de um sedutor (1991), e do livro de poemas Bufólicas (1992), obras, segundo a própria autora, imersas "[n]a problemática do sexo [colocada] de uma maneira diferente, nova, chula" (entrevista à Marie Claire, 1991, p. 22, apud SOUZA, ibidem).

Tal embate, todavia, em vez de nivelar a obra hilstiana então nascente a modelos para- ou subliterários, como os romances best-sellers ou as publicações pornográficas, acaba por acentuar, por meio de seu discurso irônico, a crítica da autora ao mercado editorial, que pauta seu lucro naquilo que é "fabricado em série e montado na base de algumas receitas de êxito rápido" (BOSI, 1992, p. 320). Assim, a obra final de Hilst mantém-se ainda hermética e se distancia do gosto médio das massas, porque a autora não abre mão da escrita rebuscada e formal que caracterizava toda a sua obra anterior, já afeita, de certo modo, às temáticas lírico-amorosa e erótica.

Nesse sentido, embora parte da crítica insista em classificar a obra final da autora (a trilogia obscena e Bufólicas) como pornográfica, não podemos dar a ela tal rótulo. Se em sua obra inicial encontramos ou o discurso erótico ou o lírico-amoroso, em que o primeiro "tende a se concentrar mais nos aspectos físicos do amor e da paixão, enquanto [o segundo] demora-se mais nas manifestações mais nobres do amor, os 'mais elevados' sentimentos" (CUDDON, 1999, p. 284; tradução nossa) ${ }^{3}$, como bem aponta Pécora "a crueza desses textos [os da trilogia obscena e o de Bufólicas] não tem como efeito a excitação do leitor (...) [, eles] contrariam a regra de ouro da pornografia banal, que é a simulação realista" (2010, p. 20), e devem, portanto, ser classificados como obscenos, uma vez que escritos

a partir de um ponto de vista nuclearmente obsceno, isto é, que supunha imperativo trazer à cena justamente o que se esperava que ficasse fora dela, por incomodar o leitor, ou o que for. Desejava mudar aquele que a lia, e falar de estados extremos do homem.

\footnotetext{
${ }^{3}$ No original: "[Erotic poetry] tends to concentrate on the more physical aspects of love and passion; while [love poetry] dwells more on the nobler manifestations of love, the 'higher' feelings".
} 
(PURCENO in PÉCORA [org.], 2010, p. 65; grifo nosso)

Assim, de modo geral, a poesia de Hilda Hilst encontra-se em consonância com as transformações de seu tempo, a segunda metade do século XX, e traz, portanto, em seu cerne, conforme nos aponta Coelho (1999, p. 67), as interrogações mais radicais do pensamento contemporâneo, quer "de natureza física (psíquico-erótica)", quer "de natureza metafísica (filosófico-religiosa)", reunindo em seus versos tanto a fusão amorosa de um eu feminino com o outro, quanto a tentativa de redescoberta do ser humano num espaço a meio caminho do sagrado e do profano, tudo isso proferido por uma voz que é, ao mesmo tempo, a do ser humano, a da mulher e a da poetisa, à qual

"cabe a tarefa nomeadora: a da palavra demiúrgica que cria o Real" (ibidem; grifo do original).

Seu livro Júbilo, memória, noviciado da paixão, de 1974, período em que a autora já se aventurava pela prosa, dá à poesia hilstiana uma nova e maior intensidade, distanciando-a de seus volumes de poemas anteriores e abrindo caminho para que o erotismo tome as rédeas de seu texto. O livro, assim,

promove um trajeto rumo aos intrincados espaços e processos de construção poética, em que se apresentam irmanados os conceitos de memória, esquecimento, materialidade, poesia e história. Este último conceito, aliás, abordado tanto do ponto de vista empírico, pessoal; quanto ligado à noção de coletividade (MACHADO, 2006, p. 1).

Por esses conceitos citados por Machado, cabe ressaltar, perpassa um discurso erótico que vai além da mera sexualidade como função orgânica, característica esta intrínseca à pornografia. Em Júbilo, memória, noviciado da paixão, o erotismo se realiza por meio da "experiência de comunhão plena eu-outro que, partindo do corpo, atinge as raízes metafísicas do ser e o faz sentir-se participante da totalidade" (COELHO, 1999, p. 74; grifos do original). O trabalho com a palavra e suas significações; o tecido narrativo; o jogo que deles se configura - tudo isso confirma tratar-se de um texto erótico, em que cada uma das características anteriormente mencionadas tem "a finalidade de mostrar uma representação cultural particular, singular, da sexualidade” (DURIGAN, 1985, p. 38), ainda que de maneira velada, implícita em metáforas e alegorias. 
Estruturalmente, por sua vez, o livro compõe-se de sete seções, a saber: "Dez chamamentos ao amigo", "O poeta inventa viagem, retorno, e sofre de saudade", "Moderato cantabile", "Ode descontínua e remota para flauta e oboé. De Ariana para Dionísio", "Prelúdios-intensos para os desmemoriados do amor", “Árias pequenas. Para bandolim" e "Poemas aos homens do nosso tempo", esta última, apenas, destituída quer do lirismo amoroso quer do erotismo que perpassam o restante do livro, mas conciliando em seus poemas um tom afetivo que se realiza envolto em misticismo e ideologia.

\section{O poema e sua versão: análise}

O blog "Brazilian Poetry in Translation: Translations and Transfigurations", mantido pela tradutora e poetisa Lavínia Saad, apresentou entre fevereiro de 2007 e agosto de 2012, data de sua última atividade, um total de 24 publicações de versões para o inglês de poemas dos escritores brasileiros Hilda Hilst e Paulo Lemisnki, além de poemas da própria tradutora em apresentação bilíngue.

O poema de Hilst escolhido para nossa análise é o que abre a seção "Dez chamamentos ao amigo", do livro Júbilo, memória, noviciado da paixão, e teve sua versão em inglês publicada por Saad em 5 de maio de $2007^{4}$. Neste poema, bem como em toda a seção do livro de que faz parte, percebemos um intenso e constante voltar-se do eu poético a um interlocutor que se ausenta; além deste traço dialógico, percebemos em seu discurso também um tom didático, de inspiração clássica, que se desenvolve no sentido de uma pedagogia do erótico por meio da qual a amante (o eu lírico), arrebatada, toma para si a palavra capaz de dar vida ao ato amoroso e a dirige ao amado, seu interlocutor, para, em imperativo, fazer-lhe o convite amoroso e guiar-lhe as ações.

Antes de analisarmos o trabalho da tradutora, consideremos, primeiramente, o poema original (também apresentado em seu site), que segue abaixo:

Dez chamamentos ao amigo

(I)

\footnotetext{
${ }^{4}$ A versão sofreu uma posterior alteração, em julho de 2012, segundo se depreende dos comentários feitos no blog, a partir da sugestão de uma leitora. Assim, no penúltimo verso do poema vertido para o inglês, onde antes líamos "With less haughtiness", lemos agora, no site "From a lesser height". Para efeito de nossa análise, entretanto, optamos por conservar a primeira versão de Saad, de maio de 2007.
} 
1 Se te pareço noturna e imperfeita

Olha-me de novo. Porque esta noite Olheime a mim, como se tu me olhasses.

E era como se a água

5 Desejasse

Escapar de sua casa que é o rio

E deslizando apenas, nem tocar a margem.

Te olhei. E há tanto tempo

Entendo que sou terra. Há tanto tempo

10 Espero

Que o teu corpo de água mais fraterno

Se estenda sobre o meu. Pastor e nauta

Olha-me de novo. Com menos altivez.

E mais atento. (HILST, 2001, p. 17)

Formalmente, o poema compõe-se de quatro estrofes que se agrupam pareadas em uma quintilha e um dístico, totalizando catorze versos, sem, contudo, configurar-se um soneto (poema de forma fixa tanto em relação ao número de sílabas métricas, normalmente dez ou doze, quanto em relação ao número de versos, normalmente catorze, agrupados em duas quadras e dois tercetos no modelo italiano e em três quadras e um dístico no inglês).

Os versos são livres, apresentando metrificações variadas, com distribuição irregular nas estrofes (por isso chamadas livres ou polimétricas) e com esquema irregular de rimas externas (abcdc ef gghhi jg), sem rimas internas. Tal distribuição dos versos, aliada às cesuras (pausas no interior do verso que o dividem em segmentos melódicos, como no interior dos versos $2,3,7,8,9,12$ e 13), às pausas finais (dos versos $1,3,6,7$, 12 e 13) e aos enjambements (quebras da pausa final entre a última palavra de um verso e a primeira do seguinte, como entre os versos 2-3, 4-5-6, 8-9-1011-12) dão ao texto um ritmo também ele caudaloso, qual a imagem do rio suscitada no poema, ora deslizando-se entre os enjambements, ora amaneirando-se nas pausas e cesuras. Além disso, também influem no ritmo do poema suas aliterações (a repetição do mesmo som em fonemas consonânticos dentro do mesmo verso ou estrofe, sendo chamada de eco quando envolve as sílabas finais) em /m/, /s/ e /t/, destacadas em itálico, e suas assonâncias (a repetição do mesmo som em fonemas vocálicos dentro do mesmo verso ou estrofe) em /a/, /ã/ e /ẽ/, 
sublinhadas: "te pareço noturna e imperfeita", "olheime a mim, como se tu me olhasses",

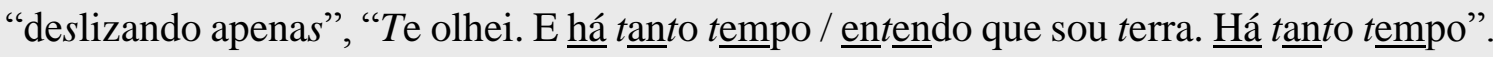

Estruturalmente, notamos, primeiramente, a ausência do pronome reto de primeira pessoa. Apenas pronomes oblíquos aparecem, em geral átonos, mas também um tônico, sempre com a função de objeto direto do verbo 'olhar': "olha-me”, "olheime a mim" (neste caso, temos uma construção reflexiva, com objeto direto pleonástico [a forma tônica "a mim" repete o sentido da átona "me"]) . O pronome reto de segunda pessoa aparece uma única vez (verso 3), visto que os demais verbos flexionados em segunda pessoa encontram-se no modo imperativo, reforçando o tom didático mencionado anteriormente. O oblíquo (átono) de segunda pessoa também se liga a verbos visuais: "te pareço", "te olhei”. Os possessivos, tanto com função substantiva como adjetiva, aparecem três vezes: um de primeira (“o meu”), um de segunda (“teu”) e outro de terceira pessoa (“sua”) - este ligando as palavras 'água' e 'casa'.

Os verbos são a classe gramatical predominante, aparecendo dezoito vezes, e entre eles o verbo 'olhar' é o que mais se repete (cinco vezes). Em seguida temos os substantivos (treze), e entre eles os únicos a se repetir são 'água' e 'tempo', duas vezes cada; além disso, restringem-se basicamente a três campos semânticos: 'tempo'

(“tempo”, “noite”), ‘água' (“água”, “rio”, “nauta”) e “terra' (“terra”, “margem”, “pastor”). Há apenas quatro adjetivos, dois deles referindo-se ao eu poético ("noturna", “imperfeita"), e os demais, ao interlocutor ("fraterno", "atento"). As demais palavras são artigos, conjunções, preposições, pronomes demonstrativos e relativos, advérbios e locuções adverbiais.

Tomemos agora a versão em língua inglesa do mesmo poema:

Ten Calls to a Friend

1 If I seem to you nocturnal and imperfect Look at me again. Because tonight I looked at myself as if you were looking at me.

And it was as if water

5 Desired 
To leave your house that is the river, Just slipping by, not even touching the riverbank.

I looked at you. And it has been so long

That I understand that I am earth. It has been so long

10 That I wait

For your brotherly body of water

To stretch over mine. Pastor and naut

Look at me again. With less haughtiness.

And more attentively. (SAAD, 2007)

Formalmente, a versão conserva a maior parte das características do poema original, como as quatro estrofes pareadas em uma quintilha e um dístico, num total de catorze versos. Além disso, os versos mantêm-se livres, mas o esquema de rimas externas desaparece quase por completo (conserva-se apenas a rima em "long", nos versos 8 e 9). Os enjambements e as pausas finais se conservam, mas há o apagamento da cesura do terceiro verso do poema, em virtude da queda da vírgula (existente no original) imposta pela própria língua-alvo (“I looked at myself as if you were looking at me”).

O número de aliterações, ecos e assonâncias amplia-se consideravelmente. Nos exemplos a seguir, vemos aliterações e ecos em /b/, /f/, /nd/, /s/, /t/ e / / /, destacados em itálico, e de assonâncias em /æ/,/an/, /e/, /I/, /aI/ e /o/, sublinhadas, o que preserva ou mesmo estende, na língua-alvo, as nuanças e variações de sonoridade do poema, impondolhe ritmos novos, mas ainda caudalosos, como os descrevemos, anteriormente, em relação ao original: "I $f$ I seem to you nocturnal and imperfect", "And it was as if water", "To leave your house that is the river", "Just slipping by", "That $I$ understand that $I$ am earth", "For your brotherly body of water", "Wịth less haughtinesss".

Estruturalmente, entretanto, é que notamos as maiores alterações. Primeiramente, há agora uma abundância de pronomes retos de primeira pessoa, dada a obrigatoriedade da presença do pronome sujeito na língua inglesa, procedimento tradutório a que Barbosa (1990, p. 68) dá o nome de explicitação (a saber, de elementos cuja presença é obrigatória na língua-alvo, mas não na língua-fonte). Os oblíquos também aparecem, exercendo o mesmo papel que no original; o objeto direto pleonástico presente neste último, todavia, 
desaparece, dando lugar apenas ao pronome reflexivo no texto em inglês, passando de "olhei-me a mim" a "I looked at myself"

(verso 3 de ambos os poemas). O pronome reto de segunda pessoa aparece uma única vez (verso 3), visto que os demais verbos flexionados em segunda pessoa encontram-se no modo imperativo. Os pronomes possessivos aparecem três vezes, um de primeira ("mine") e dois de segunda pessoa ("your") - isso em virtude de um erro de tradução, ao se traduzir o possessivo de terceira pessoa ("sua"), que liga as palavras "água" ("water") e "casa" ("house"), por um de segunda, sem que o mesmo, no original, faça referência ao interlocutor (o que se deve à ambiguidade do possessivo de terceira pessoa no português brasileiro ['seu' e variantes] quando usado em relação ao pronome de tratamento 'você'); assim, no trecho mencionado (verso 6), o correto deveria ser "To leave its house that is the river", com o possessivo aqui destacado referindo-se ao substantivo neutro "water" (verso 4).

Os verbos continuam sendo a classe gramatical predominante, aparecendo dezoito vezes, e entre eles o verbo 'look' é o que mais se repete (cinco vezes). Neste grupo, entretanto, há uma mudança de tempo verbal que causa alteração de sentido ao se comparar os textos fonte e alvo: o verso 3, "olhei-me a mim como se tu me olhasses", ao ser traduzido utilizando-se o verbo no tempo progressivo destacado ("I looked at myself as if you were looking at me"), atribui à comparação descrita no verso (iniciada por “as if”) um sentido de concomitância de ações inexistente no original, já que o pretérito imperfeito simples do subjuntivo ("olhasses") não passa tal ideia. Além disso, mas sem alterar o sentido original, ocorre mudança morfossintática em dois verbos: o infinitivo "tocar" é traduzido pelo gerúndio "touching”, por demanda da língua-alvo (verso 7), e o complemento oracional do verbo 'esperar', nos versos 10 a 12, cuja conjunção integrante destacamos, "espero/ que o teu corpo (...)/ se estenda (...)" passa a ligar-se à oração "I wait/ for" sob a forma reduzida de infinitivo "to stretch".

Ainda quanto à ocorrência, em seguida aos verbos temos os substantivos (nove), que se reduzem em virtude das diferenças entre as locuções temporais que os utilizam em português, mas não em inglês (procedimento tradutório conhecido como transposição, descrito por Barbosa como a alteração de classe gramatical de elementos traduzidos [ibidem, p. 66]); assim, os substantivos ficam restritos basicamente a dois campos semânticos: ‘água' (“water", "river”, "naut”) e 'terra' (“earth”, "riverbank”, “pastor”). Os adjetivos também se alteram, uma vez que há transposição de dois deles, que passam a 
advérbio ("fraterno" > "brotherly", "atento" > "attentively"). Ainda assim, a tradutora conserva, com sucesso, as imagens e os sentidos propostos pelo original: um poema de ambientação noturna, com imagens que contrapõem terra e água e em que o interlocutor é, a todo o momento, incitado a corresponder o olhar do eu lírico.

As demais palavras são artigos, conjunções, preposições, pronomes demonstrativos e relativos, advérbios e locuções adverbiais, com duas omissões: a da conjunção "e" em "E deslizando apenas" (verso 7), omitida na tradução, e a do advérbio "mais" em "mais fraterno" (verso 11), traduzido apenas por "brotherly". Quanto às preposições e às conjunções integrantes, algumas (destacados a seguir) são inseridas na versão inglesa por imposição de uma regência verbal ou nominal distinta daquela em língua portuguesa: assim, "olha-me" passa a "look at me" (versos 2 e 13); "deslizando", a "slipping by" (verso 7); "espero" (transitivo direto), a "wait for" (transitivo indireto; verso 10), e "há tanto tempo", a "it has been so long that" (versos 8 e 9), respectivamente; apenas uma preposição da língua de origem é omitida na de destino, também em função da transitividade verbal, que passa de indireta a direta, a saber, "escapar de sua casa" traduzse por "to leave your house" (verso 6; reiteramos a ressalva feita anteriormente quanto à tradução equivocada do possessivo your neste verso).

Há, por fim, no antepenúltimo verso, uma escolha de tradução que julgamos inadequada: levando-se em consideração que a palavra pastor, em inglês, é raramente utilizada com o sentido do termo latino (pastor, -oris) de que se origina, qual seja, o de 'indivíduo que apascenta um rebanho', cremos que a melhor tradução para o termo 'pastor', presente no original, seja a palavra inglesa shepherd, cuja primeira acepção é justamente a suscitada pelo texto, o que se justifica pelo próprio universo semântico do poema, próximo ao da poesia clássica, como vemos pela escolha vocabular, feita por Hilst, de palavras como 'pastor' e 'nauta', 'terra' e ‘água', 'margem' e 'rio'.

\section{Conclusão}

Ao final desta análise, tendo em mente o que discutimos a respeito das características do texto literário, do exercício tradutório e da obra hilstiana, cremos ter reunido recursos suficientes para fazer um balanço da versão por nós analisada, tanto em 
termos estilísticos quanto técnicos. Comparando-se os dois poemas, o original e sua versão em língua inglesa, percebemos que a tradutora logrou êxito, de fato, em trazer para seu texto a atmosfera, as imagens, o ritmo e o sentido do poema hilstiano, preservando-lhe a linguagem elevada do eu lírico que clama por seu interlocutor enquanto guia seu olhar, linguagem esta fortemente imagética, de ritmo e forma caudalosos em sua sonoridade e cadência, de um lado, e em sua disposição gráfica a mesclar versos e estrofes breves e longos, de outro.

Também tecnicamente a tradutora executou a contento o trabalho tradutório, exibindo bom domínio linguístico e de escrita, seja em termos semânticos ou sintáticos: demonstra conhecimento da língua inglesa padrão, o que lhe permitiu tanto dar fluidez e correção ao texto como adequar sua escolha lexical ao universo semântico do poema - os dois pequenos equívocos por nós apontados em nada desqualificam seu trabalho. As transposições, explicitações, omissões e demais alterações sintáticas ocasionadas pelas necessidades da língua de destino demonstram seu domínio técnico e nos permitem verificar que o método tradutório escolhido por Saad para compor sua versão do poema é a tradução literal, ou seja, a composição de um novo texto, uma reescrita, que busca manter a fidelidade semântica para com o original, mas que, ao mesmo tempo, abre espaço às adequações morfossintáticas exigidas pela língua-alvo.

Qual um espelho imperfeito, portanto, tal trabalho tradutório revela não uma imagem simétrica, exata, mas outra, nítida o suficiente para se recuperar a imagem original; ou, em outras palavras, elabora um texto poético autônomo que se sustenta como tal na língua de chegada, sem, no entanto, deixar de evocar aquele que o originou.

\section{Referências}

BARBOSA, H. G. Procedimentos técnicos da tradução: uma nova proposta. Campinas, SP: Pontes, 1990.

BOSI, A. Dialética da civilização. São Paulo: Companhia das Letras, 1992.

COELHO, N. N. Da poesia (ensaios). Cadernos de literatura brasileira, São Paulo, n. 8, p. 66-79, out. 1999. 
CUDDON, J. A. Dictionary of Literary Terms \& Literary Theory. Londres: Penguin Books, 1999.

DE CAUSATIS, B. A tradução literária: uma arte conflitual. Cadernos de tradução, Florianópolis, v. 2, n. 22, p. 9-34, jul.-dez. 2008.

DURIGAN, J. A. Erotismo e literatura. São Paulo: Ática, 1985.

FURLAN, M. Possibilidade(s) de tradução(ões). Cadernos de tradução, Florianópolis, v. 1, n. 3, p. 89-111, jan.-dez. 1998.

HILST, H. Júbilo, memória, noviciado da paixão. São Paulo: Globo, 2001.

MACHADO, S. Evocações memoriais do amor: o corpo como síntese e origem. Revista Garrafa, Rio de Janeiro, n. 9, mai.-jul. 2006.

PAZ, O. O arco e a lira. Rio de Janeiro: Nova Fronteira, 1982.

PAZ, O. Tradução, literatura e literariedade. Belo Horizonte: FALE/UFMG, 2006.

PÉCORA, A. Nota do organizador. In: PÉCORA, A. (Org.). Por que ler Hilda Hilst. São Paulo: Globo, 2010, p. 7-29.

PURCENO, S. O obsceno objeto de desejo de HH. In: PÉCORA, A. (Org.). Por que ler Hilda Hilst. São Paulo: Globo, 2010, p. 64-92.

SAAD, L. Ten Calls to a Friend (I). Brazilian Poetry in Translation: Translations and Transfigurations (Website). Disponível em: <http://brazilpoetry.blogspot.com.br/2007/05/hilda-hilst-ten-calls-to-friend.html>. Acessado: em 1 dez. 2010.

SOUZA, R. C. de S. e. A (des)construção irônica da pornografia na trilogia obscena de Hilda Hilst. Rio de Janeiro, 2008. 132 f. Dissertação (Mestrado em Letras Vernáculas Literatura Brasileira) - Universidade Federal do Rio de Janeiro.

Recebido em 29 de setembro de 2014 Aceito para publicação em 15 de dezembro de 2014 